\title{
Famílias e adoções: um estudo bibliográfico
}

\author{
Families and adoptions: a bibliographic study \\ Familias y adopciones: un estudio bibliográfico
}

Recebido: 18/10/2021 | Revisado: 26/10/2021 | Aceito: 27/10/2021 | Publicado: 31/10/2021

Djaniffer dos Anjos
ORCID: https://orcid.org/0000-0003-3853-7148
Centro Universitário para o Desenvolvimento do Alto Vale do Itajaí, Brasil
E-mail: djaniffer.anjos@ unidavi.edu.br
Michela Iop
ORCID: https://orcid.org/0000-0003-1419-0039
Centro Universitário para o Desenvolvimento do Alto Vale do Itajaí, Brasil
E-mail: michela@ unidavi.edu.br

\begin{abstract}
Resumo
Pais/cuidadores suficientemente bons favorecem o desenvolvimento emocional saudável - a curto, médio e longo prazo - de seus filhos, assim, é interessante pensar nos sujeitos carentes destas figuras e que ficam à mercê da adoção. O objetivo geral é responder como se caracterizam as pesquisas sobre família e adoção, os específicos buscam identificar as configurações familiares estudadas neste contexto, elencar as subáreas de conhecimento que estudaram esta interface e listar as contribuições da psicologia. Este é um estudo bibliográfico, descritivo e exploratório. A partir de buscas nas bases de dados BDTD, BVS, BVS-Psi, Google Acadêmico, PePSIC e SciELO, foram selecionadas 147 pesquisas sendo todas enquadradas na modalidade de campo, nacionais e publicadas na última década, portanto, entre 2010 à 2019. Descobriu-se que as configurações estudadas foram as heterossexuais, homossexuais e monoparentais. Onze foram as subáreas pesquisadoras do tema. Várias e significativas são as contribuições da psicologia. Considerase por fim que as pesquisas se caracterizam ricas em determinados assuntos e pobres em tantos outros.
\end{abstract}

Palavras-chave: Adoções; Famílias; Pesquisa.

\begin{abstract}
Good enough parents/caregivers favor the healthy emotional development - in the short, medium and long term - of their children, thus, it is interesting to think about the individuals in need of these figures and who are at the mercy of adoption. The general objective is to answer how the researches on family and adoption are characterized, the specific ones seek to identify the family configurations studied in this context, list the sub-areas of knowledge that studied this interface and list the contributions of psychology. This is a bibliographical, descriptive and exploratory study. From searches in the BDTD, BVS, BVS-Psi, Academic Google, PePSIC and SciELO databases, 147 researches were selected, all framed in the field, national and published in the last decade, therefore, between 2010 and 2019. It was found that the settings studied were heterosexual, homosexual and single parent. Eleven were the research sub-areas of the subject. Psychology's contributions are several and significant. Finally, it is considered that the researches are characterized as rich in certain subjects and poor in many others.
\end{abstract}

Keywords: Adoptions; Families; Research.

\section{Resumen}

Los padres / cuidadores suficientemente buenos favorecen el sano desarrollo emocional - a corto, medio y largo plazo - de sus hijos, por ello, es interesante pensar en los individuos que necesitan estas figuras y que están a merced de la adopción. El objetivo general es responder cómo se caracterizan las investigaciones sobre familia y adopción, las específicas buscan identificar las configuraciones familiares estudiadas en este contexto, enumerar las subáreas de conocimiento que estudiaron esta interfaz y enumerar los aportes de la psicología. Se trata de un estudio bibliográfico, descriptivo y exploratório. A partir de búsquedas en las bases de datos BDTD, BVS, BVS-Psi, Academic Google, PePSIC y SciELO, se seleccionaron 147 investigaciones, todas enmarcadas en el campo, nacionales y publicadas en la última década, por tanto. entre 2010 y 2019. Se encontró que los entornos estudiados fueron heterosexuales, homosexuales y monoparentales. Once fueron las subáreas de investigación del tema. Las contribuciones de la psicología son varias y significativas. Finalmente, se considera que las investigaciones se caracterizan por ser ricas en ciertos temas y pobres en muchos otros.

Palabras clave: Adopciones; Familias; Buscar. 


\section{Introdução}

Desde sua mais tenra idade, os seres humanos demandam auxílio para desenvolverem-se da melhor forma possível a curto, médio e longo prazo. Auxílio este que colaborará para seu desenvolvimento psicológico, emocional e social. Winnicott (2005) afirma que o primeiro ano de vida é marcado por muitos acontecimentos, sendo um destes o desenvolvimento emocional, que, por sua vez recebe influências do ambiente externo desde os primeiros instantes de vida.

Segundo Miller (1997), a criança precisa ser, desde o seu nascimento, respeitada em todos os seus aspectos e contextos e necessita uma mãe que a espelhe e esteja disponível para atender suas necessidades. Existindo esta mãe, é provável que a criança desenvolva sentimentos saudáveis a respeito de si e dos outros. "Toda criança tem a legítima necessidade de ser notada, compreendida, levada a sério e respeitada pela mãe. Nas primeiras semanas e meses de vida necessita ter a mãe à disposição, usá-la e espelhar-se nela.” (Miller, 1997, p. 39)

Winnicott (2005) relata a necessidade de uma mãe minimamente sadia. Esta mãe deverá executar seu papel de maneira adequada correspondendo às necessidades do bebê. Para Winnicott (2005), a figura materna tem importância ímpar, uma vez que influencia significativamente os comportamentos que favorecem o desenvolvimento emocional do bebê. Deixa explícito Winnicott (2005), a mãe como figura principal para o desenvolvimento saudável do bebê. Souza (2011) preocupa-se com a qualidade da relação inicial que se traçará entre cuidadores e criança e não em uma figura específica. Portanto, o que importa é a forma como os pais, membros da família e outros possíveis cuidadores irão se relacionar com o bebê.

Sobre a importância dos vínculos e relações primárias, Bowlby (1989), defensor da teoria do apego, diz que durante a primeira infância os vínculos entre criança e seus pais/substitutos servem para proteção, conforto e suporte. A maneira como se constroem e a forma como ocorrem são imprescindíveis uma vez que o reflexo de tais relações perdura durante todo o ciclo vital e por consequência, ditam a forma de relacionar e comportar-se no mundo. Podendo, com isso, afetar sua saúde e desenvolvimento emocional.

Uma vez a família sendo a primeira fonte de relações, falar sobre relações primárias implica falar sobre famílias. Segundo Wagner, Tronco e Armani (2011), com a pluralização das configurações familiares não se admite mais tratá-las no singular, assim, fala-se sobre famílias e não mais família. Moreira (2013) expõe algumas configurações familiares hoje conhecidas: monoparentais (constituídas pela mãe ou pai), conviventes (podem ou não terem outras pessoas coabitando junto sem serem da mesma consanguinidade), recasadas (homem ou mulher casam-se com quem já possui filhos), colaterais (composta apenas por irmãos) e homoparentais (casais constituídos por pessoas do mesmo sexo que possuem filhos de relações heterossexuais anteriores). Walsh (2016) complementa que famílias adotivas, constituídas por uma só pessoa e as compostas de cônjuges do mesmo sexo sem filhos, estão tornando-se mais frequentes.

Carter e McGoldrick (2001) inferem que o sistema familiar sofre influências emocionais de pelo menos três a quatro gerações. Ou seja, as relações que operam no círculo familiar estão sob a influência de relacionamentos multigeracionais, assim, direta ou indiretamente todos têm, ou terão, ligações com aqueles que já fizeram parte de seu sistema familiar ou que um dia irão fazer. Inevitavelmente existe uma mistura de gerações e por isso aquilo que acontece em um determinado nível terá efeitos colaterais nos níveis futuros. É por isso que as famílias e suas relações são de extrema importância para a construção individual. Falcke e Wagner (2005) afirmam que as relações firmadas dentro da família na qual se nasce ou convive são as mais importantes da vida de uma pessoa pois servirão de base para seus comportamentos futuros. Para Abuchaim et al. (2016), as famílias devem proporcionar relações primárias capazes de construírem vínculos seguros. A vinculação segura permitirá ao sujeito autonomia e coragem para explorar o mundo pois lhe dará coragem para recuar e retornar ao seu seio familiar.

Dada a importância das figuras de cuidado e das relações familiares, é oportuno pensar nos indivíduos adotados já que em sua maioria são seres que carecem de tais dispositivos. Ao contrário do que se pensa a adoção não é uma prática atual. Segundo Weber (2015), desde a antiguidade todos os povos convivem com o abandono e, por consequência, com atos jurídicos 
que buscam prevalecer a criação ou manutenção de laços afetivos familiares. Desde seu surgimento na população romana, a adoção sofreu várias mudanças, tanto no que se refere à sua compreensão e objetivos quanto às leis que normatizam o seu desempenho. Primordialmente e de forma geral, a adoção possuía simples caráter de sucessão familiar; já nos dias atuais, após decretos, leis, resoluções e estatutos, ela passa a ser vista como um ato de amor onde o que prevalece é o interesse do adotado e não mais do adotante.

Entre os motivos para se adotar, Weber (2000) elenca: ajudar o adotado, realizar a vontade de ser pai/mãe, poder de escolha do sexo do filho, ter um ajudante nas tarefas domésticas, "substituição" de um filho falecido e outros. Para Weber (2000), a decisão de adotar sofre grande influência de valores morais e religiosos, mostrando com isso que infelizmente o assunto é regado por tabus. Dentre os mitos mais comuns cita o medo do desconhecimento do histórico de saúde e doença do indivíduo a ser adotado assim como de sua família biológica, desconhecimento da idoneidade moral dos pais biológicos, receando assim aspectos de marginalidade, prostituição e outros que acreditam serem transmitidos para a criança de forma hereditária, racismo, poder ou não escolher a criança que se quer, adotar crianças em idade tardia, temor por não amar tanto filhos adotivos quanto biológicos e medo de que os pais ou família biológica queiram novamente o adotado.

Perante o exposto, importa verificar até onde e quais são os assuntos mais estudados nacionalmente sobre a adoção, almejando conhecer o que trazem as pesquisas acerca da temática, além de identificar quais as necessidades de novas pesquisas na área, assim, responde-se a problemática: como se caracterizam as pesquisas produzidas sobre família e adoção? O objetivo geral norteador deste questionamento foi: caracterizar, por meio da revisão bibliográfica, estas pesquisas. Os específicos buscaram identificar quais foram as configurações familiares estudadas no contexto da adoção, investigar quais subáreas do conhecimento têm se debruçado a estudar a interface família e adoção e elencar as contribuições da psicologia no processo adotivo.

\section{Metodologia}

Esta é uma pesquisa bibliográfica, enquadrada nas modalidades descritiva e exploratória. Para Gil (2017), a pesquisa bibliográfica tem como base materiais já publicados, propondo-se estudar a posição de determinado autor sobre determinado assunto, ou ainda, investigar todos os resultados já existentes sobre um assunto específico. Segundo Gil (2002), a pesquisa descritiva estabelece ligação entre variáveis, seu principal objetivo é descrever as características de dada população ou fenômeno, já as exploratórias proporcionam maior familiaridade com o problema e seu principal objetivo é aprimorar ideias ou exibir suspeitas.

Os critérios de inclusão usados para filtragem das pesquisas foram a) ano e nacionalidade, b) leitura dos títulos e resumos e c) leitura dos títulos, resumos e métodos. Já os de exclusão ficaram com a) pesquisas duplicadas, b) estudos abordando outra temática e c) que não fossem pesquisas de campo. As plataformas de dados utilizadas foram a Biblioteca Digital Brasileira de Teses e Dissertações (BDTD), Biblioteca Virtual de Psicologia Brasil (BVS), Biblioteca Virtual em Saúde - Psicologia Brasil (BVS-Psi), Google Acadêmico, Periódicos Eletrônicos de Psicologia (PePSIC) e Scientific Eletronic Library Online (SciELO). Utilizou-se os descritores adoção, crianças adotadas, crianças adotivas, filhos adotados, filhos adotivos, impactos da adoção e psicologia e adoção. Selecionou-se os materiais de origem nacional, publicados na última década e correspondentes a pesquisas de campo. Realizou-se a leitura dos títulos, resumos e métodos dos materiais restando apenas aqueles que respondessem aos objetivos desta pesquisa. Por fim, a fim de separar os arquivos em temas/categorias, foi executada as quatro etapas de leitura estabelecidas por Gil (2017): exploratória, seletiva, analítica e interpretativa.

\section{Resultados e Discussão}

A busca crua - apenas utilizando os descritores - em todos os bancos de dados possibilitou 4.086 pesquisas. Com os 
critérios de inclusão e exclusão, os números reduziram-se conforme segue: inclusão do ano e nacionalidade para 520, com a leitura dos títulos e resumos chegou-se em 187 e por fim, com a leitura dos títulos, resumos e métodos, restaram 147. Para a construção da análise e discussão dos dados utilizaram-se efetivamente 69 das 147 pesquisas selecionadas. A partir de temáticas recorrentes foram criadas categorias equivalentes a cada objetivo que são expostos a seguir.

\subsection{Família Ê, Família A, Família}

As configurações heterossexuais, homoafetivas e monoparentais foram as estudadas.

\subsubsection{Configuração Familiar Heterossexual}

Para Oliveira, Souto e Silva Júnior (2017), a adoção é sentida como um gesto de amor, doação, entrega, responsabilidade, um ato que possibilita ajudar quem não tem família assim como permite a construção de uma (nova) família. Infertilidade, impossibilidade de gestar a completude familiar são alguns dos motivos para adotar. A felicidade plena e a amplitude familiar são algumas das expectativas proporcionadas pela a adoção. Oliveira (2014b) observou outros três motivos para se adotar: o fato de ser adotado, filhos biológicos possuírem doenças geneticamente transmissíveis e manutenção de um relacionamento conjugal desajustado.

Segundo Bicca e Grybowski (2014), a adoção tardia repercute em desafios para o casal: mudanças na rotina conjugal, redução na carga horária dedicada ao trabalho para se dedicar ao filho (percebido prioritariamente nas mães), problemas de saúde e temores com doenças genéticas do adotado, mudanças na rotina alimentar, aquisição de vestimentas, brinquedos, acentuada preocupação de pertencimento familiar no adotado, dificuldades em criar vinculação parento-filial, preconceito e adversidades escolares. Mas apontam que a própria idade é um aspecto positivo da adoção tardia, assim, é vista como facilitador do desenvolvimento de relações satisfatórias, pois o sujeito compreender melhor sua adoção adaptando-se à nova realidade. O adotado tardiamente não é tão dependente quanto um bebê. Para Sampaio, Magalhães e Féres-Carneiro (2018), receio das vivências anteriores, problemas advindos dos cuidados básicos com a higiene pessoal, defasagem no desenvolvimento, comportamentos agressivos no início da adoção e oposição ao estabelecimento e cumprimento de regras são alguns dos desafios da adoção tardia. Para Otuka, Scorsolini-Comin e Santos (2013), a adoção tardia causa incitações no adotado com a necessidade de adaptar-se repentinamente a um novo ambiente físico e familiar, "obrigação" para lidar com seus sentimentos e medos (principalmente de um reabandono) e demandas emocionais que requerem cuidados.

Conforme Otuka, Scorsolini-Comin e Santos (2012), tanto a parentalidade biológica quanto a adotiva em sua maioria não são planejadas ou desejadas inicialmente. A parentalidade biológica é experenciada como satisfatória para os pais/mães e a possibilidade da paternidade biológica traz sentimentos de potência diante da fertilidade do casal, sobretudo ao homem. As dificuldades relatadas nas adoções são a resistência inicial dos filhos biológicos, problemas de saúde do adotado, resistência e preconceito familiar do adotante, adversidades comportamentais refletindo no desenvolvimento escolar e dificuldades na revelação da história biológica do filho. O relacionamento fraterno é saudável, mas há disputa em relação ao amor e preferência da família. Percebe-se maior proteção com o filho adotivo.

\subsubsection{Configuração Familiar Homoafetiva}

Amazonas, Veríssimo e Lourenço (2013) apontam que a orientação sexual não se apresenta como empecilho para o amadurecimento e conclusão da vontade de ser pai/mãe. Para Farias (2012), este desejo provém da perda de filhos anteriores, da infertilidade e pelo prazer de estar com crianças. Segundo Tombolato, Maia e Santos (2019), o desejo de ser pai/mãe não é acompanha a vida dos homossexuais, ao contrário, surge apenas quando estes envolvem-se em uma relação afetiva ou quando estabilizados financeiramente. 
Para Farias (2017), a orientação sexual gera divergências de pensamentos entre os próprios membros da família de origem/externa do adotante. Assim, há em uma única família, pessoas que aceitam e apoiam a orientação sexual como quem não aceita e nem apoia. Geralmente, aqueles que não aceitam, consequentemente não apoiam a decisão de adotar, existindo, aqui, uma confusão entre orientação sexual e papeis de gênero. Segundo Zanardo (2014), a família extensa, quando não respeitosa, apresenta comportamentos de subtrair o convívio com o adotado. Farias (2017) afirma que o preconceito familiar está atrelado a questões religiosas e estereótipos sociais. Amazonas, Veríssimo e Lourenço (2013) apontam que muitos pais temem a revelação de sua sexualidade aos filhos por medo da confusão e reação que podem os acometer, receiam serem rejeitados ou não mais amados pelos mesmos. Para Farias (2012), esse temor resulta na preferência por adotar crianças menores, de no máximo três anos. Existem a apreensão que ao revelar sua sexualidade, isso influenciará na sexualidade ou personalidade dos filhos. Para Alves (2018), a verdade sobre a origem da filiação é fundamental pois desperta no adotado confiança e pertencimento. Para Mota, Vargas e Vasconcelos (2015) ocultar a história da filiação biológica/adotiva, gera exatamente o que os pais temem: problemas emocionais no adotado e dificuldades nas relações familiares.

Para Silva et al. (2017), homossexuais são menos exigentes em relação às características de seu filho, para eles, o importante é amar e não serem fisicamente parecidos. Conforme Fender (2016), pais/mães menos levam menos tempo para efetivar a adoção. Farias (2012) diz que a preferência é por crianças menores (máximo três anos). Os adotantes acreditam que sujeitos maiores podem carregar o preconceito sobre a homossexualidade. O sexo feminino, por ser classificado menos propenso a sofrer preconceito por terem pais gays ou mães lésbicas é o mais querido. Outros pensamentos preconceituosos são avaliados pela autora, como quando homens mencionam que gostariam de serem pais de meninos para poderem jogar futebol.

Meletti e Scorsolini-Comin (2015) observam que a divisão das tarefas domésticas e gastos mensais são assuntos que invocam forte adaptação na conjugalidade. Fender (2016) indica mudanças no círculo de convívio social e na relação sexual após a chegada de filhos. Contrapondo, Zanardo (2014) aponta que após a chegada do filho, nenhum desajuste ocorre na relação do casal, ao contrário, o relacionamento melhora e as discussões diminuem. Para Farias (2017), conflitos conjugais pós parentalidade são reflexos de problemas não resolvidos na dinâmica conjugal, podendo resultar em problemas de adaptação no adotado.

Santos et al. (2018) pesquisando as representações sociais da população sobre a adoção homoafetiva, descobriram que a maioria dos entrevistados se sentem favoráveis desde que existam condições dignas para o desenvolvimento saudável do adotado. A maioria destes favoráveis são heterossexuais, contudo, suas falas contradizem-se, pois, entendem que o mais adequado seria uma adoção heterossexual, já que os sujeitos filhos de homossexuais tendem a sofrer mais preconceito e com isso serem reféns de problemas psicológicos. A adoção por um casal de mulheres foi bem mais aceita do que entre homens. O público LGBT participante da pesquisa mostrou-se mais assertivo e defensor da adoção homoafetiva. Cerqueira-Santos e Santana (2015) investigando as crenças dos estudantes de direito e serviço social, observaram que estes acreditam que homossexuais são mais promíscuos, usam mais drogas, expõem-se mais às doenças sexualmente transmissíveis, afastam-se mais da religião, são mais sensíveis do que os heterossexuais e pensam que filhos de homossexuais podem ser homossexuais. De outro lado, acreditam que homossexuais batalham mais do que heteros, são mais criativos e animados.

\subsubsection{Configuração Familiar Monoparental}

Para Santos et al. (2011), a adoção é uma forma de lidar com a perda de um ente querido, nestes casos, a aceitação familiar é muito mais assertiva e há maior união entre os membros. Esta aceitação é menos evidente nas adoções tardias sendo. Silva e Cavalcante (2015) dedicaram-se a estudar de qual forma o tempo é aproveitado entre pai/mãe-filho nas adoções de pessoas com deficiências. Descobriram que são realizadas atividades que proporcionam contato físico e emocional, como: descanso, lazer, escolar, higiene e alimentação. 


\subsection{Quem Estuda o Quê?}

Apresentar-se-á as subáreas do conhecimento estudantes da interface família e adoção.

\subsubsection{Antropologia}

Finamori e Silva (2019) discutem a interrelação entre identidade e pertencimento familiar nos grupos de apoio à adoção. Estes grupos apresentam consciência do direito e da importância da revelação da adoção/origem biológica para o adotado. Falar sobre isso gera medo tanto nos pais quanto nos filhos. Já Correia (2011) investigou como psicólogas jurídicas percebem a homoafetividade e se suas significações interferem em seu trabalho. Não se percebeu problemas quanto a homossexualidade para a concretização da adoção, mas sim, inquietações acerca do gênero e suas respectivas tarefas em lares homoafetivos.

\subsubsection{Ciências Sociais Aplicadas}

Oliveira (2016) estudou os grupos de apoio estão envolvidos nas adoções, especialmente o Grupo de Apoio às Adoções Necessárias (GAAN), ou seja, adoções tardias. O GAAN é uma ferramenta útil para a preservação da cidadania das crianças e adolescentes que se encontram em processos adotivos, além de trabalhar com esse público trabalham com a preparação dos postulantes à adoção (quando a preparação é eficaz, as chances das devoluções são bem menores). As atividades realizadas contemplam debates desde os procedimentos burocráticos até mitos sobre a adoção. Os membros do GAAN objetivam garantir a cidadania dos adotados.

\subsubsection{Desenvolvimento Humano}

Pinto, Oliveira e Coutinho (2011) investigaram a dinâmica de uma família nuclear com filhos adotivos. Perceberam que a adoção foi realizada com o objetivo de atingir o desejo pessoal do casal de se tornarem pais. A dinâmica é composta por uma interação e interdependência nas relações entre os membros familiares assim como na relação com outros sistemas. Essa interação e interdependência colabora para que os membros atinjam seus objetivos familiares e pessoais.

\subsubsection{Direito}

Collet (2011), em sua pesquisa com profissionais das Varas da Infância e Juventude das Comarcas Catarinenses, mostrou dados importantes sobre as adoções tardias por famílias estrangeiras no estado de Santa Catarina: irmãos e crianças maiores aumentam cada vez mais, o tempo de permanência de crianças e adolescentes em abrigos está extrapolando e por isso as adoções tardias aumentam, o aumento do número de crianças maiores ou irmãos que não são adotados reflete na má preparação dos postulantes a adoção, o que por sua vez repercuti na má atuação dos profissionais envolvidos na habilitação e pós-adoção, o Tribunal da Justiça precisa atualizar a matriz de capacitação de seus funcionários e aumentar o quadro de psicólogos para que estes possam atuar de forma adequada nos processos avaliativos, pré e pós-adoção, aproximadamente $70 \%$ das Comarcas Catarinenses não realizam adoções internacionais apresentando resistência a essa possibilidade além de gastar tempo desnecessário com a família biológica, as esquipes técnicas das Varas da Infância e Juventude devem vincular-se com a criança/adolescente, necessário disponibilizar atendimento psicológico aos abrigados e a preparação do sujeito a ser adotado deve incluir noções básicas do idioma falado por seus novos pais assim como a preparação dos pais deve incluir a língua portuguesa pois na adoção estrangeira o idioma é um fator indicativo do (in)sucesso da vinculação.

\subsubsection{Ecoetologia Humana}

Oliveira (2013) estudando a adoção tardia de gêmeo relata que devido à relação parento-filial se dar no cotidiano, é 
necessário a preparação dos pretendentes pré, durante e após a adoção, há situações que o confronto entre a filiação idealizada e a real gera frustações e dificuldades. O período de preparação deve abarcar informações concretas e fidedignas do sujeito a ser adotado, considerando que omissões são preditores de problemas na relação familiar. Defende que a licença maternidade de 30 dias nos casos de adoção é curtíssima.

\subsubsection{Educação}

Cruz (2018) descobriu que a comunidade escolar apresenta significados negativos sobre a adoção. Essa negativa pode justificar-se pela falta de conhecimento e preparo para lidar com a temática. Sinaliza a necessidade de qualificar profissionalmente todo o corpo institucional. Ao fazer esse aperfeiçoamento os profissionais possuem suporte para compreender melhor os aspectos legais da adoção e com isso melhorar sua interação com os sujeitos adotados. O foco da interação deve visar especialmente uma relação mais acolhedora por parte da instituição escolar a fim de que indivíduos em processos adotivos ou adotados não sejam excluídos ou negligenciados neste ambiente.

\subsubsection{Enfermagem}

Segundo Lage, Santos e Nazareth (2014), a esterilidade, doença de um dos cônjuges e o não querer engravidar são motivos para adotar. A adoção possui dois objetivos: possibilitar ao sujeito desprovido de família uma nova história e proporcionar aos pais o exercício de paternidade. Ressaltam a importância de não negar as preferências dos pais, pois em casos onde suas escolhas não são consideradas, as chances do filho adotivo ser negligenciado é muito maior, mas alertam que quanto mais características forem selecionadas maior será o tempo na fila de espera. O tempo de espera não é apenas um momento de aflição e ansiedade, é neste período que os pais vivenciam o processo de adaptação à nova realidade, passando pela gestação psicológica. Nota-se que as mães que conseguem amamentar mesmo não tendo engravidado realizam-se enquanto pessoa e mãe. Para muitas mulheres, o fato de não ter gerado o filho é menos frustrante do que não conseguir amamentá-lo.

\subsubsection{Família na Sociedade Contemporânea}

Araújo (2017) identificou motivos para mulheres optarem pela adoção: infertilidade, mudança no cotidiano conjugal, altruísmo e quando os filhos biológicos já são adultos surge a necessidade de dar sentido à vida. Identificou os motivos para devolução dos filhos por estas mesmas mães: comportamentos inesperados do filho durante o período de convivência familiar, não correspondência do amor e gratidão que fora esperado pelo adotante e receio que o adotado traga características da família biológica. As repercussões emocionais que atingem essas mães expressam sentimentos de ambivalência durante todo o processo adotivo, acentuando-se nos momentos conflituosos. Após a devolução a culpa é o sentimento que domina as mães. A devolução é traumatizante e muitas delas adiam ou até mesmo desistem de uma nova adoção.

\subsubsection{Psicologia}

Bortolatto, Loos e Delvan (2016) mencionam que ao compartilharem experiências, os grupos de apoio à adoção colaboram com a redução da ansiedade dos postulantes durante o período de espera, assim, os grupos são percebidos como uma rede de apoio emocional para os participantes. Oliveira e Pereira (2011) mostram que os profissionais das Varas de Infância e Juventude relatam a importância de grupos de irmãos não serem separados, expressam preocupação quanto ao tempo que crianças/adolescentes ficam abrigados em instituição de acolhimento e mencionam a dificuldade de reduzir este período pelo fato de não condizerem com o perfil desejado pelos adotantes. Tornar-se filho a partir da adoção tardia, segundo Araujo (2017) é um ato super valorizado pelo adotado. $\mathrm{O}$ adotado tardiamente define que viver no novo ambiente familiar lhe proporciona pertencimento, amor e valia. Mozzi e Nuernberg (2019) expressam que adoções de pessoas deficientes mostram 
que o vínculo que os pais estabelecem com os filhos e o reconhecimento que estes possuem acerca da adoção possibilitar igualmente a parentalidade são suas principais motivações. Outro motivador é a redução de 01/05 anos para 03/18 meses de espera para findar a adoção. As dificuldades para estas adoções são condições financeiras e preparo psicológico dos candidatos. Muniz (2016) elenca motivos para as devoluções: diferença no tratamento entre filhos biológicos e adotivos, desmembramento de irmãos biológicos e idealização da família biológica ou adotiva versus a família real. Os impactos da devolução são a agressividade física ou verbal para com os membros da instituição de acolhimento, rejeição frente a uma nova adoção, negação da devolução, isolamento, tristeza, raiva, dificuldades escolares ou cognitivas, culpabilização e problemas com o sono. Rodrigues e Hueb (2019) dizem que a preparação do filho biológico para a chegada do irmão adotivo é fundamental, os pais precisam dar espaço para que os filhos expressem seus sentimentos quanto ao novo irmão. Mesmo com a preparação, o filho consanguíneo pode sofrer emocionalmente. A chegada do novo irmão é experimentada por sentimentos de ambivalência e por este motivo é normal que o primogênito busque atenção na tentativa de firmar seu pertencimento na família e amor de seus pais. Oliveira (2014a) apresenta as estratégias e critérios utilizados por psicólogos judiciários enquanto assistentes técnicos na avaliação dos postulantes: apoiar-se nos trabalhados realizados pelos Grupos de Apoio à Adoção, utilizar entrevistas e técnicas projetivas, identificar aspectos importantes como motivação para adoção, idealização da criança, medos e resistências frente ao desejo de adotar, o grau de respeito quanto à história anterior da criança, capacidade para exercer as funções parentais, os vínculos familiares entre pretendentes e sua família externa, o lugar que o adotado ocupará na família, capacidade de elaboração do luto pela impossibilidade do filho biológico, capacidade de empatia e etc. Antes de mais nada, se prioriza a qualidade do vínculo entre os pretendentes e a criança/adolescente.

\subsubsection{Serviço Social}

Bezerra (2016) tratou da adoção tardia e diz que assim como na filiação biológica, a adoção é um processo que exige demasiado vínculo emocional, portanto, nas duas filiações corre-se o risco de insucessos e dificuldades. Adoção tardia ocorre a partir dos cinco anos de idade. A preferência por bebês é o motivo de crianças/adolescentes não serem tão requisitados, felizmente as exigências pela menor idade estão diminuindo, indivíduos com idade superior a dois anos estão sendo mais procurados. A maior preocupação alusiva à adoção tardia é que o acolhimento demasiado colabora em dificuldades na construção dos vínculos familiares. Vale (2013) investigou a adoção realizada por idosos. O índice de idosos em busca de adoção é baixíssimo podendo estar atrelado ao fato de não estarmos preparados para lidar com mudanças nos papeis sociais. Há divergências entre a legislação e a realidade. Enquanto o judiciário não impede que idosos adotem, assistentes sociais percebem no simbólico do fator idade um agravante, resultando assim em poucas solicitações de idosos pela a adoção.

\subsubsection{Sociologia}

Pinto (2018) investigou se há diferenças na educação simultânea de filhos biológicos e adotivos, descobrindo que há diferenças, não pelo fato de serem biológicos ou adotivos, mas sim porque cada pessoa é única. Nas famílias biológicasadotivas a educação prevalente é o modelo autoritário, nessas famílias, o apoio, afeto, comunicação e etc. são distribuídos em iguais níveis entre seus membros.

\subsection{Contribuições da Psicologia Frente à Adoção}

Para Contente, Cavalcante e Silva (2013), a psicologia contribui com a adoção desmistificando seus tabus. Ao trabalhar com essa questão colabora com a redução de ideias equivocadas, preconceitos e inquietações que angustiam os pretendentes à adoção. Para Tibola e Kemmelmeier (2012), as contribuições estão nos acompanhamentos realizados com o adotado, famílias e abrigos. Cabe o acompanhamento e orientação em casos de menores infratores, perícias familiares, 
acompanhamento das famílias, encaminhamentos médicos dos jovens abrigados, orientação para a comunidade escolar e acompanhamento nas instituições que prestam apoio aos abrigos. Avaliar a relação entre irmãos abrigados é uma tarefa importantíssima da psicologia, a desmembração de irmãos só deve acontecer em últimos casos. Silva (2012) expõe que os psicólogos exercem atividades importantes como a reinserção familiar e quando não possível, contribuem com a confecção de relatórios técnicos cujo objetivo é a perda do poder familiar.

\section{Considerações Finais}

Como se caracterizam as pesquisas produzidas sobre família e adoção? Essa foi a pergunta norteadora deste estudo e é chegada a hora de respondê-la. Após coletar, analisar e discutir os achados, percebe-se que as pesquisas que tratam desta temática caracterizam-se, ao mesmo tempo, como ricas em determinados assuntos, mas pobres em tantos outros. Por exemplo, muitas foram as pesquisas que trataram sobre as concepções, motivações medos e outros aspectos subjetivos que os candidatos à adoção possuem acerca do tema, porém, poucas foram as que buscaram compreender a adoção a partir da ótica do adotado. Tendo em vista que o melhor interesse da adoção é sempre ao adotado, parece contraditório que os pesquisadores não deem voz a esse público.

Pode-se citar o elevado número de documentos produzidos com famílias heterossexuais enquanto outras parecem esquecidas. Aqui, existe outra contradição, por mais que tenham mais pesquisas com famílias heteros, foram nos estudos com famílias homoafetivas que se visualizou maior aprofundamento nos assuntos abordados. Considera-se que há nas pesquisas realizadas com famílias homoafetivas maior riqueza de informações do que nas executadas com famílias heterossexuais, reforçando assim a ideia que quantidade nem sempre é qualidade.

Identificou-se que dentre todas as pesquisas realizadas com pais e mães adotantes, a maioria foram executadas apenas com os pais, uma parcela menor com ambos e a minoria com as mães. Evidenciou-se que na configuração familiar monoparental essa estimativa diverge, pois as mães foram as mais requisitadas, sendo a participação dos pais quase nula. Podese justificar essa ponderação pelo o fato de lares comandados por mulheres estarem expressivos atualmente. De acordo com o último censo realizado com famílias pelo Instituto Brasileiro de Geografia e Estatística (IBGE, 2010), o número de famílias que conviviam em domicílios era de 4.381.256, sendo que destes, 2.342 .003 condiziam apenas a mulheres-mães que chefiavam seus lares. Dado este dado, levanta-se outra reflexão. Como foi exposto, os números de estudos realizados com famílias monoparentais adotantes foram baixíssimos e sabendo que esta configuração familiar está em evidência, é interessante para o meio acadêmico que os próximos pesquisadores, que almejam estudar a temática adoção, deem atenção a essa configuração familiar.

Ressalta-se a baixa produção de documentos construídos com o objetivo de investigar quais são as concepções e significados que possuem acadêmicos dos cursos de assistência social, direito e psicologia. Este dado é relevante pois é possível identificar nos estudos feitos com esses estudantes/profissionais que muitos possuem concepções não condizentes com a realidade da adoção, especialmente no tocante às diversas formas de ser família. Acredita-se que mais estudos com este público colaborará para que equívocos sejam evitados ainda em seus processos formativos, o que, refletirá em atuações profissionais mais assertivas.

Há uma tendência na repetição dos temas analisados em cada subárea de conhecimento. De modo algum pode-se dizer que essas informações são desnecessárias, contudo, assuntos estudados pela enfermagem (amamentação de filhos adotivos), psicologia (fraternidade, entregar o filho e processo de habilitação), serviço social (adoção na velhice) e sociologia (processos educativos), por praticamente serem únicos merecem destaque.

Por mais que tenha sido possível analisar as contribuições da psicologia frente à adoção existe a sensação de que este é um tema que deva ser melhor explorado, pois os resultados aparecem de forma superficial. Visto a importância do trabalho 
da psicologia para este processo é fundamental que os psicólogos estejam bem mais preparados e qualificados para trabalhar com a adoção, seja em seus aspectos legais quanto nos afetivos/emocionais e psicológicos.

Inicialmente pretendia-se realizar o estudo com os próprios adultos adotados a fim de compreender como a adoção foi por eles compreendida. Mas, por impasses do novo Coronavírus (COVID-19), ajustes foram necessários. Desejava-se ter dado voz aos adotados visto que são raras as pesquisas com este público. Espero que a partir das ponderações aqui feitas, este trabalho contribua e incentive para que mais pesquisas sejam realizadas na área, especialmente aquelas que foquem nos aspectos da adoção que hoje carecem de atenção.

\section{Referências}

Abuchaim, B. O. et al. (2016). Importância dos vínculos familiares na primeira infância: estudo II. Comitê Científico do Núcleo Pela Infância. São Paulo: Fundação Maria Cecilia Souto Vidigal.

Alves, J. R. (2018). A representação familiar de crianças que vivenciaram o processo de adoção em diferentes configurações de família. 123 f. Dissertação (Mestrado em Psicologia) -Universidade Federal do Triângulo Mineiro. http://bdtd.uftm.edu.br/handle/tede/548.

Amazonas, M. C. L. A., Verissimo, H. V., \& Lourenço, G. O. (2013). A adoção de crianças por gays. Psicologia \& Sociedade, Belo Horizonte. 25(3), 631641. https://doi.org/10.1590/S0102-71822013000300017.

Araujo, I. C. C. (2017). Tornar-se filho na perspectiva de crianças adotadas tardiamente. 191 f. Dissertação (Mestrado em Psicologia) -Universidade Federal do Espírito Santo. http://repositorio.ufes.br/handle/10/6876.

Araújo, M. I. (2017). A devolução de crianças na adoção tardia e a construção da maternidade. 127 f. Dissertação (Mestrado em Família e Sociedade Contemporânea) -Universidade Católica do Salvador, Salvador. http://ri.ucsal.br:8080/jspui/handle/prefix/389.

Bezerra, S. M. N. (2016). Adoção tardia e direito à convivência familiar na perspectiva dos profissionais do juizado da infância e da juventude de Fortaleza Ceará. 152 f. Dissertação (Mestrado Acadêmico em Serviço Social) -Universidade Estadual do Ceará, Fortaleza. http://siduece.uece.br/siduece/trabalhoAcademicoPublico.jsf?id=83642.

Bicca, A., \& Grzybowski, L. S. (2014). Adoção tardia: percepções dos adotantes em relação aos períodos iniciais de adaptação. Contextos Clínicos, São Leopoldo. 7(2), 155-167. https://dx.doi.org/10.4013/ctc.2014.72.04.

Bortolatto, M. O., Loos, V. N., \& Delvan, J. S. (2016). Grupos de apoio à adoção e o sucesso das adoções. Barbarói, Santa Cruz do Sul, 48, 205-233. https://doi.org/10.17058/barbaroi.v0i48.8319.

Bowlby, J. (1989). Uma base segura: aplicações clínicas da teoria do apego. Ed.Artes Médicas.

Calderón, A. I. et al. (2016). Novos desafios e demandas à comunidade escolar: a escola e a educação de crianças adotadas por famílias gays. 695-704. https://www.defensoria.sp.def.br/dpesp/Repositorio/39/Documentos/novos_desafios_e_demandas_a_comunidade_escolar.pdf.

Carter, B., \& McGoldrick, M. (2001). As mudanças no ciclo de vida familiar: uma estrutura para a terapia familiar. (2a ed.), Ed.Artmed.

Cerqueira-Santos, E. et al. (2017). Contato interpessoal com homossexuais e crenças sobre a adoção homoparental. Revista Subjetividades, Fortaleza. 17(2), 87-100. https://dx.doi.org/10.5020/23590777.rs.v17i2.5991.

Collet, C. S. (2011). A adoção tardia de crianças e adolescentes por famílias estrangeiras e o direito à convivência familiar e comunitária: um estudo em Santa Catarina. 168 f. Dissertação (Mestrado em Direito) -Universidade Federal de Santa Catarina, Florianópolis. https://repositorio.ufsc.br/xmlui/handle/123456789/95599.

Contente, S. R., Cavalcante, L. I. C., \& Silva, S. S. C. (2013). Adoção e preparação infantil na percepção dos profissionais do juizado da infância e juventude de Belém/PA. Temas psicol., Ribeirão Preto. 21(2), 317-333. http://pepsic.bvsalud.org/scielo.php?script=sci_arttext\&pid=S1413389X2013000200002\&lng=pt. http://dx.doi.org/10.9788/TP2013.2-02.

Correia, A. L. F. (2011). O psicólogo jurídico frente à adoção homoafetiva: práticas, sentidos e possibilidades. 115 f. Dissertação (Mestrado) -Universidade Federal de Pernambuco, Recife. https://repositorio.ufpe.br/handle/123456789/730.

Cruz, S. A. (2018). Adoção de crianças maiores e adolescentes: representações sociais de gestores escolares. $150 \mathrm{f}$. Dissertação (Mestrado em Educação) Universidade Católica de São Paulo, São Paulo. https://tede2.pucsp.br/handle/handle/21482.

Falcke, D., \& Wagner, A. (2005). A dinâmica familiar e o fenômeno da transgeracionalidade: definição de conceitos. In Wagner, A. Como se perpetua a família? a transmissão dos modelos familiares. Ed.ediPUCRS.

Farias, C. M. C. (2012). A adoção por casais homoafetivos como concretização do direito ao melhor interesse das crianças e adolescentes. 164 f. Dissertação (Mestrado em Direito Constitucional) -Universidade de Fortaleza, Fortaleza. http://bdtd.ibict.br/vufind/Record/UFOR_0b13fac202fa9e1432e40ca188957a19.

Farias, M. O. (2017). Experiências e vivências de famílias homoafetivas com filhos: vozes de pais, mães e filhos. 386 f. Dissertação (Mestrado em Psicologia Social) -Universidade Católica de São Paulo, São Paulo. https://tede2.pucsp.br/handle/handle/20512. 
Fender, M. F. (2016). A experiência e os desafios da adoção por pais que se declaram homossexuais. 98 f. Dissertação (Mestrado em Psicologia) Universidade Católica de São Paulo, São Paulo. https://tede2.pucsp.br/handle/handle/19382.

Finamori, S., \& Silva, A. B. M. (2019). Identidade e pertencimento: grupos de apoio à adoção e direito às origens. Sex., Salud Soc., 33, 295-317. https://doi.org/10.1590/1984-6487.sess.2019.33.14.a.

Gil, A. C. (2002). Como elaborar projetos de pesquisa. (4a ed.), Ed.Atlas.

Gil, A. C. (2017). Como elaborar projetos de pesquisa. (6a ed.), Ed.Atlas.

Instituto Brasileiro de Geografia e Estatística. (2010). Censo demográfico 2010: amostra-famílias. https://cidades.ibge.gov.br/brasi 1/pesquisa/23/24161?detalhes=true.

Lage, S. R., Santos, I. M. M., \& Nazareth, I. V. (2014). Narrativa de vida de mulheres que amamentaram seus filhos adotivos. Revista Rene. 15(2), 249-256. $<$ https://pesquisa.bvsalud.org/portal/resource/pt/lil-721866.

Meletti, A. T., \& Scorsolini-Comin, F. (2015). Conjugalidade e expectativas em relação à parentalidade em casais homossexuais. Psicologia: teoria e prática, São Paulo. 17(1), 37-49. http://pepsic.bvsalud.org/scielo.php?script=sci_arttext\&pid=S1516-36872015000100004\&lng=pt\&nrm=iso.

Miller, A. (1997). O drama da criança bem dotada: como os pais podem formar (e deformar) a vida emocional dos filhos. Ed.Summus.

Moreira, M. I. C. (2013). Novos rumos para o trabalho com famílias. Ed. NECA - Associação dos Pesquisadores de Núcleos de Estudos e Pesquisas sobre a criança e o adolescente.

Mota, M. M., Vargas, M. M., \& Vasconcelos, T. T. (2016). Filiação adotiva por pares homoafetivos: um estudo do processo e significados para famílias protagonistas. Interação em Psicologia, Curitiba. 19(2), 161-172. http://dx.doi.org/10.5380/psi.v19i2.21219.

Mozzi, G., \& Nuernberg, A. H. (2016). Adoção de crianças com deficiência: um estudo com pais adotivos. Paidéia, Ribeirão Preto. 26(63), 101109. http://www.scielo.br/scielo.php?script=sci_arttext\&pid=S0103-863X2016000100101\&lng=en\&nrm=iso.

Muniz, F. M. R. P. (2016). “Adoções” que não deram certo: o impacto da “devolução” no desenvolvimento da criança e do adolescente na perspectiva de profissionais. 138 f. Dissertação (Mestrado em Psicologia Clínica) -Universidade Católica de Pernambuco, Recife. http://tede2.unicap.br:8080/handle/tede/246.

Oliveira, J. (2016). Grupo de apoio à adoção: desenvolvimento da cidadania em relação à adoção. 102 f. Dissertação (Mestrado em Sociedade, Direito e Cidadania) -Universidade Estadual de Ponta Grossa, Ponta Grossa. https://tede2.uepg.br/jspui/handle/prefix/241.

Oliveira, M. L. S. (2013). Adoção tardia de gêmeos: estudo de caso de uma família adotante. 80 f. Dissertação (Mestrado em Ecoetologia Humana) Universidade Federal do Pará, Belém. http://repositorio.ufpa.br/jspui/handle/2011/11098.

Oliveira, P. A. B. A., Souto, J. B., \& Silva Junior, E. G. (2017). Adoção e psicanálise: a escuta do desejo de filiação. Psicologia: Ciência e Profissão, Brasília. 37(4), 909-922. https://doi.org/10.1590/1982-3703003672016.

Oliveira, R. R. (2014a). Os critérios utilizados por assistentes técnicos judiciários psicólogos na avaliação de pretendes à adoção. 101 f. Dissertação (Mestrado em Psicologia) -Universidade de São Paulo, São Paulo. https://www.teses.usp.br/teses/disponiveis/47/47133/tde-01102014-160510/pt-br.php.

Oliveira, T. C. F (2014b). Filho do coração: o processo de adoção de crianças na perspectiva paterna. 173 f. Dissertação (Pós-Graduação em Família) Universidade Católica do Salvador, Salvador. http://bdtd.ibict.br/vufind/Record/UCSAL-1_c3d61be576f90fd49e5321d050c58bdc.

Otuka, L. K., Scorsolini-Comin, F., \& Santos, M. A. (2012). Adoção suficientemente boa: experiência de um casal com filhos biológicos. Psicologia: Teoria e Pesquisa, Brasília. 28(1), 55-63. https://doi.org/10.1590/S0102-37722012000100007.

Otuka, L. K., Scorsolini-Comin, F., \& Santos, M. A. (2013). Adoção tardia por casal divorciado e com filhos biológicos: novos contextos para a parentalidade. Estudos de Psicologia, Campinas. 30(1), 89-99. https://doi.org/10.1590/S0103-166X2013000100010.

Pinto, H. C. T. (2018). Processos educativos em famílias com filhos biológicos e adotados. 39 f. Dissertação (Mestrado em Educação e Sociedade) -Instituto Universitário de Lisboa. https://repositorio.iscte-iul.pt/handle/10071/17259.

Pinto, T. O., Oliveira, M. M.., \& Cotinho, E. K. (2011). Análise ecossistêmica de uma família com filhos adotivos. Oikos: Família e Sociedade em Debate. 22(2), 171-194. https://periodicos.ufv.br/oikos/article/view/3615.

Rodrigues, A. C. F., \& Hueb, M. F. D. (2019). O impacto emocional de se tornar irmão pela adoção: um estudo de caso coletivo. Contextos Clínicos, São Leopoldo. 12(3), 751-778. https://dx.doi.org/10.4013/ctc.2019.123.03.

Sampaio, D. S., Magalhães, A. S., \& Feres-Carneiro, T. (2018). Pedras no caminho da adoção tardia: desafios para o vínculo parento-filial na percepção dos pais. Trends in Psychology, Ribeirão Preto. 26(1), 311-324. https://doi.org/10.9788/TP2018.1-12Pt.

Santos, C. P. et al. (2011). Adoção por pais solteiros: desafios e peculiaridades dessa experiência. Psicologia: Teoria e Prática, 13(2), 89-102. http://pepsic.bvsalud.org/scielo.php?script=sci_arttext\&pid=S1516-36872011000200007\&lng=pt\&nrm=iso.

Santos, J. V. O. et al. (2018). Adoção de crianças por casais homossexuais: as representações sociais. Trends in Psychology, 26(1), 139-152. https://doi.org/10.9788/TP2018.1-06Pt>. ISSN 2358-1883. https://doi.org/10.9788/TP2018.1-06Pt.

Silva, F. H. O. B., \& Cavalcante, L. I. C. (2015). Rotinas familiares de crianças com necessidades especiais em família adotiva. Psicologia: Teoria e Pesquisa, Brasília. 31(2), 173-180. https://doi.org/10.1590/0102-37722015021920173180. 
Research, Society and Development, v. 10, n. 14, e213101421990, 2021

(CC BY 4.0) | ISSN 2525-3409 | DOI: http://dx.doi.org/10.33448/rsd-v10i14.21990

Silva, M. L. (2012). Lei nacional de adoção e acolhimento institucional: o ponto de vista de psicólogos e assistentes sociais. 227 f. Dissertação (Mestrado em Psicologia) -Universidade Federal de Santa Maria, Santa Maria. https://repositorio.ufsm.br/handle/1/10304.

Silva, P. S et al. (2017). Diferentes configurações familiares de candidatos à adoção: implicações para os processos de habilitação. Estudos de psicologia, Natal. 22(4), 412-421. http://dx.doi.org/10.22491/1678-4669.20170042.

Souza, S. R. (2011). Saúde integral da criança. In Cypel, S. (Org.). Fundamentos do desenvolvimento infantil: da gestação aos 3 anos. Ed.Fundação Maria Cecília Souto Vidigal.

Tibola, V. B., \& Kemmelmeier, V. S. (2012). Trabalho interprofissional em fóruns: sua importância nos casos de adoção. Psicologia Argumento, Curitiba. 30(71), 691-701. http://www2.pucpr.br/reol/pb/index.php/pa?dd1=7475\&dd99=view\&dd98=pb.

Tombolato, M. A., Maia, A. C. B., \& Santos, M. A. (2019). A trajetória de adoção de uma criança por um casal de lésbicas. Psicologia: Teoria e Pesquisa, Brasília. 35 e 3546, 1-11. https://doi.org/10.1590/0102.3772e3546.

Vale, C. B. (2013). Adoção na velhice: limites e possibilidades. 100 f. Dissertação (Mestrado em Gerontologia) -Pontifica Universidade Católica de São Paulo, São Paulo. https://tede2.pucsp.br/handle/handle/12434.

Wagner, A., Tronco, C., \& Armani, A. B. (2011). Os desafios da família contemporânea: revisitando conceitos. In Wagner, A. et al. Desafios psicossociais da família contemporânea: pesquisas e reflexões. Ed.Artmed.

Walsh, F. (2016). Processos normativos da família: diversidade e complexidade. (4a ed.), Ed.Artmed.

Weber, L. N. D. (2000). Aspectos psicológicos da adoção. Ed. Juruá.

Weber, L. N. D. (2015). O psicólogo e as práticas de adoção. In Gonçalves, H. S., \& Brandão, E. P. (Org.). Psicologia jurídica no Brasil. (3a ed.), Ed.NAU.

Winnicott, D. W. (2005). A família e o desenvolvimento individual. (3a ed.), Ed.Martins Fontes.

Zanardo, L. B. (2014). Laços de afeto: as homoparentalidades pela via da adoção. 212 f. Dissertação (Mestrado em Psicologia e Sociedade) -Universidade Estadual Paulista, Assis. http://hdl.handle.net/11449/116025. 